\title{
Selection of SDM: A Fuzzy AHP Approach
}

\author{
Kri. Sandhya \\ M. Tech Scholar, \\ BITM, \\ Santiniketan W.B., \\ India
}

\author{
H.B. \\ Mahapatra \\ Research Scholar, \\ JRU, \\ Ranchi,Jharkhand \\ , India
}

\author{
Birendra \\ Goswami \\ Asst. Prof. ICFAI \\ University, \\ Ranchi, India
}

\author{
Pinaki Pratim \\ Acharjya \\ Asst. Prof. BITM, \\ Santiniketan W.B., \\ India
}

\begin{abstract}
When developing software, the selection of an appropriate software development methodology (SDM) is an essential decision. There are many SDM exist that are used to control the process of developing a software process. No exact system was found which could guide software engineers for selection of a proper methodology during software development. This paper show factor affecting the selection of SDM and the consistency in which the methodology selection carried out. Based on Fuzzy AHP, we evaluate the consistency in SDM selection. This paper presents a framework of Fuzzy AHP approach for selection of three different SDM with their three conflicting selecting criteria alternatives.
\end{abstract}

\section{Keywords}

Fuzzy analytical hierarchy process( FAHP), Software development methodology

\section{INTRODUCTION}

This article presents a theoretical framework for selection of an appropriate SDM. The goal of developing this framework is to guide software developer for decision making about selection and evaluation of SDM through Fuzzy AHP approach.

Most of the software fails during the development and even after development and not delivered in stipulated time period, which may create problem for software development organization in context of their reputation and reliability in IT industry [1]. Selection of various SDM required to develop software in optimal manner is very essential to avoid all these problems. Decision making is very necessary for various problems and becomes tedious and difficult if the qualities of the alternatives are conflicting. A suitable method can be applied to deal this type of problem. Multi criteria decision making methods are widely used to solve this type of problem. Criteria of alternatives may be quantitative and qualitative based on these a suitable MCDM method like fuzzy AHP is applied in this piece of research work [1].

Before dealing my paper we must have little discussion over SDM and their selecting criteria. A software process model can be defined as a strategy, comprising process, methods and tools layer as well as the general phases for developing the software. It provides a basis for controlling various activities required to develop and maintain the software [2].

IEEE defines a software process model as "A framework containing the processes, activities and tasks involved in the development, operation and maintenance of a software product, spanning the life of the system from the definition of its requirements to the termination of its use". It provides a flexible framework for enhancing the process. It enables effective communication, facilitates process reuse and facilitates process management [2].
There are various kinds of software process model or SDM such as: Waterfall model, Prototype model, Spiral model, Incremental model, Time-boxing model, RAD model etc. The SDM framework is specific to the project. Thus, it is essential to select the SDM according to software. The software project is considered efficient if the process model is selected according to the requirements. It is also essential to consider time and cost while choosing a process model as cost and / or time constraints play an important role in SDM [2]. The basic characteristics required to select the process model are Requirement specification, Cost, Time, Project type, Project size and Change incorporate [3]. This selection may be based on expertise or heuristic manner, which sometime fails due to uncertainty involved. Hence MCDM based Fuzzy AHP used for selection of SDM for software development

Very few literatures are available on this topic In 2005, M.AYMAN AL AHMAR [4] present object oriented modeling and development of a rule based expert systems for selecting suitable SDM according to S/w project features. In 2011, Abdur Rashid khan, Zia Ur Rehman and Hafeez Ullah Amin [5] present knowledge-based system for process model selection known as ESPMS for selecting SDM. This paper focused some technology like Fuzzy logic, certainty factors and Analytical Hierarchy process (AHP) for developing ESPMS. In 2014, Jyoti verma, Sunita Bansal, Himanshu pandey [3] present a rule base expert system combined with likert scale measurement for selecting best SDM and develop a tool named as Modset.

In this paper, we deals with selecting criteria of SDM and compare different SDM with their features .These comparisons are used for ranking SDM using Fuzzy AHP. Here we use only three SDM and their three major features for selection of SDM. In future, we extent it with more SDM and their more features.

\section{PROPOSED WORK}

In this section we introduce, proposed work which shown below in 5 steps:

1. Study of different SDM and their selecting criteria.

2. Comparison of methodology according to their features.

3. Study of MCDM Fuzzy AHP approach.

4. Use FAHP in Software engineering for SDM selection.

5. Choose appropriate SDM.

\subsection{Software Development Methodology}

A software development methodology describes an environment that is used to organize, plan and direct the 
process of developing a software system. There are many software development methodologies and these methodologies contain some basic stages of software development life cycle. These stages are planning, analysis, design, implementation and maintenance. There are various SDM such as Waterfall model, Spiral model, Prototype model, RAD, Incremental model so on.

In case of developing a software it is important to select an appropriate SDM. There are so many features which required to selecting the SDM such as Requirement specification, Cost, time, project size, project type and change incorporate. It is important to use methodology which have high success rate and cost effective.

\subsection{Comparison of SDM}

There are so many SDM but here we use three SDM: Waterfall model, Spiral model and Prototype model and compare this model with respect to their features [3]:

Table 1: Comparison among Waterfall, Spiral and Prototype Model:

\begin{tabular}{|l|l|l|l|}
\hline Features & Waterfall & Spiral & Prototype \\
\hline $\begin{array}{l}\text { Req. } \\
\text { Specification }\end{array}$ & Beginning & $\begin{array}{l}\text { Frequently } \\
\text { changed }\end{array}$ & Beginning \\
\hline $\begin{array}{l}\text { Complexity of } \\
\text { system }\end{array}$ & Simple & Moderate & Complex \\
\hline Time schedule & Very low & Long & Long \\
\hline Cost & Low & High & Expensive \\
\hline Documentation & Necessary & Yes & Yes \\
\hline Project size & $\begin{array}{l}\text { Large } \\
\text { scale }\end{array}$ & $\begin{array}{l}\text { Low or } \\
\text { medium }\end{array}$ & $\begin{array}{l}\text { Large } \\
\text { scale }\end{array}$ \\
\hline $\begin{array}{l}\text { Change } \\
\text { incorporate }\end{array}$ & Difficult & Easy & Easy \\
\hline
\end{tabular}

\subsection{Multi criteria Decision Making Technique}

Multi criteria decision making is a method to deal with the process of making decision among number of alternatives with conflicting criteria on them. AHP is one of the very popular MCDM methods and fuzzy AHP is an extension of original AHP method suggested by saaty[6] to deal with qualitative and quantitative data. Therefore, we discuss first AHP then Fuzzy AHP.

\subsubsection{Analytical Hierarchy Process (AHP):}

One of the most popular analytical techniques for complex decision-making problem is the analytic hierarchy process (AHP).Analytic Hierarchy Process (AHP) proposed by Saaty $(1980,2000)[6]$, is an approach for decision making that involves structuring multiple choice criteria into a hierarchy, assessing the relative importance of these criteria, comparing alternatives for each criterion, and determining an overall ranking of the alternatives.

The main procedure of AHP using the geometric mean method is as follows[7]:-

Step 1: Determine the objective and the evaluation attributes.

Step 2: Determine the relative importance of different attributes with respect to the goal or objective.

- Construct a pair-wise comparison matrix using a scale of relative importance. An attribute compared with itself is always assigned the value 1, so the main diagonal entries of the pair-wise comparison matrix are all 1 and the rating is based on Saaty's nine point scale shown in table 2 .

Table 2: Saaty's Nine Point Scale

\begin{tabular}{|l|l|}
\hline $\begin{array}{l}\text { Compared to 2nd alternative, } \\
\text { the 1st alternative is }\end{array}$ & $\begin{array}{l}\text { Numerical } \\
\text { rating }\end{array}$ \\
\hline Extremely preferred & 9 \\
\hline Very strongly preferred & 7 \\
\hline Strongly preferred & 5 \\
\hline Moderately preferred & 3 \\
\hline $\begin{array}{l}\text { Intermediate judgment between two } \\
\text { adjacent judgment }\end{array}$ & $2,4,6,8$ \\
\hline
\end{tabular}

- Assuming $\mathrm{M}$ attributes, the pair-wise comparison of attribute $i$ with attribute $j$ yields a square matrix $\mathrm{B}_{\mathrm{M} \times \mathrm{M}}$ where $a_{i j}$ denotes the comparative importance of attribute $i$ with respect to $j$. In the matrix $a_{i j}=1$ if $\mathrm{i}=\mathrm{j}$ otherwise $a_{i j}=\frac{1}{a_{j i}}$

- $\quad$ Find the relative normalized weight $\left(w_{j}\right)$ of each attribute by -

(i) Calculating the geo metric mean of the i-th row, and

(ii) Normalizing the geo metric means of rows in the comparison matrix. This can be represented as:$G M_{j}=\left[\begin{array}{ll}\prod_{i=1}^{M} & a_{i j}\end{array}\right]^{1 / M}$ and $w_{j}=G M_{j} / \sum_{i=1}^{M} G M_{j}$

- Calculate matrices A3 and A4 such that

$\mathrm{A} 3=\mathrm{A} 1 \times \mathrm{A} 2 \quad$ equation (1)

And A4= A3/A2, equation (2)

Where A2 $=[\mathrm{w} 1, \mathrm{w} 2, \ldots \ldots, \mathrm{wi}]^{T}$

- Determine the maximum Eigen value $\lambda_{\max }$ that is the average of matrix A4.

- Calculate the consistency index $\mathrm{CI}=$ $\left(\lambda_{\max }-M\right) /(M-1)$

- Obtain the random index (RI) for the number of attributes used in decision making as $\mathrm{RI}=1.987(\mathrm{n}-$ $2) / n$ where $n=$ number of attribute. Here $n=3$ then $\mathrm{RI}=0.66$ used.

Calculate the consistency ratio $\mathrm{CR}=\mathrm{CI} / \mathrm{RI}$. Usually, a $\mathrm{CR}$ of 0.1 or less is considered as acceptable and is reflects an informed judgment attributable to the knowledge of the analyst regarding the problem understudy.

Step 3: The next step is to compare the alternatives pair-wise with respect to how much better they are in satisfying each of the attributes, i.e., to ascertain how well each alternative serves each attribute.

Step 4: The next step is to obtain the overall or composite performance scores for the alternatives by multiplying the relative normalized weight (wj) of each attribute (obtain in step two) with its corresponding normalized weight value for each alternative (obtain in step three) and summing over the attributes for each alternative. 


\subsubsection{Fuzzy Analytic Hierarchy Process (FAHP)} Method:

The AHP was developed in the 1980s by Saaty [6]. It is a systematic decision making method which includes both qualitative and quantitative techniques. It is being widely used in many fields for a long time. But one of the critical steps of AHP method is to set up the comparison matrixes. When the number of attributes (or alternatives) in the hierarchy increases, more comparisons between attributes (or alternatives) need to be made. This could easily cause confusion due to the excess of questions and hence the efficiency of the model. So a consistency check is required for the pair-wise comparison matrix. Therefore, whether the setting of the comparison matrix is scientific affects the correctness of AHP directly. When the comparison matrices are not consistent, we should adjust the elements in the matrix and carry out a consistency test until they are consistent. This arrangement takes more time therefore to reduce the arrangement time Fuzzy AHP is used.

The FAHP [8] method is an advanced analytical method which is developed from the AHP. In spite of the popularity of AHP, this method is often criticized for its inability to adequately handle the inherent uncertainty and imprecision associated with the mapping of the decision-maker's perception to exact numbers. In FAHP method, the fuzzy comparison ratios are used to be able to tolerate vagueness. There is a problem with AHP that in some situations, Decision maker wants to use the uncertainty while performing the comparisons of the alternatives. For taking uncertainties into consider ration fuzzy numbers are used instead of crisp numbers. Therefore in Fuzzy AHP instead of fuzzy number crisp number is used.

The method proposed by Chen and Hwang (1992)[7] first converts linguistic terms into fuzzy numbers and then the fuzzy numbers into crisp scores. The method is described as below-

\subsubsection{Converting Linguistic terms to fuzzy numbers}

This method systematically converts linguistic term into their corresponding fuzzy numbers. It contains eight conversion scales. The conversion scales were proposed by synthesizing and modifying the works of Wenstop(1976), Bass and Kwakernaak(1977),Efstathiou and Rajkovic (1979),Kerre (1982) and Chen (1988).

\subsubsection{Converting Fuzzy Numbers to Crisp Scores}

The method uses a fuzzy scoring approach that is a modification of the fuzzy ranking approaches proposed by Jain(1976) and Chen(1985).The crisp score of fuzzy number ' $\mathrm{M}$ ' is obtained as follows:

$\mu_{\max }(\mathrm{x})=\left\{\begin{array}{l}\mathrm{x}, 0 \leq \mathrm{x} \leq 1 \\ 0, \text { otherwise }\end{array}\right.$

$\mu_{\text {min }}(x)=\left\{\begin{array}{l}1-x, 0 \leq x \leq 1 \\ 0, \text { otherwise }\end{array}\right.$

The fuzzy max and fuzzy min of fuzzy numbers are defined in a manner such that absolute location of fuzzy numbers can be automatically incorporated in the comparison cases. The right score of each fuzzy number Mi is defined as:-

$\mu_{\mathrm{R}}(\mathrm{Mi})=\operatorname{Sup}\left[\mu_{\max }(\mathrm{x})^{\wedge} \mu_{\mathrm{Mi}}(\mathrm{x})\right]$

And the left score is-

$\mu_{\mathrm{L}}(\mathrm{Mi})=\operatorname{Sup}\left[\mu_{\min }(\mathrm{x})^{\wedge} \mu_{\mathrm{Mi}}(\mathrm{x})\right]$

The total score of a fuzzy number Mi is defined as:-

$\mu_{\mathrm{T}}(\mathrm{Mi})=\left[\mu_{\mathrm{R}}(\mathrm{Mi})+1-\mu_{\mathrm{L}}(\mathrm{Mi})\right] / 2$

\subsubsection{Demonstration of the method}

Now, the 5-point scale is considered to demonstrate the conversion of fuzzy number into crisp scores. To demonstrate the method, a 5-point scale having the linguistic terms like low, below average, average, above average and high as shown in below figure is considered as:

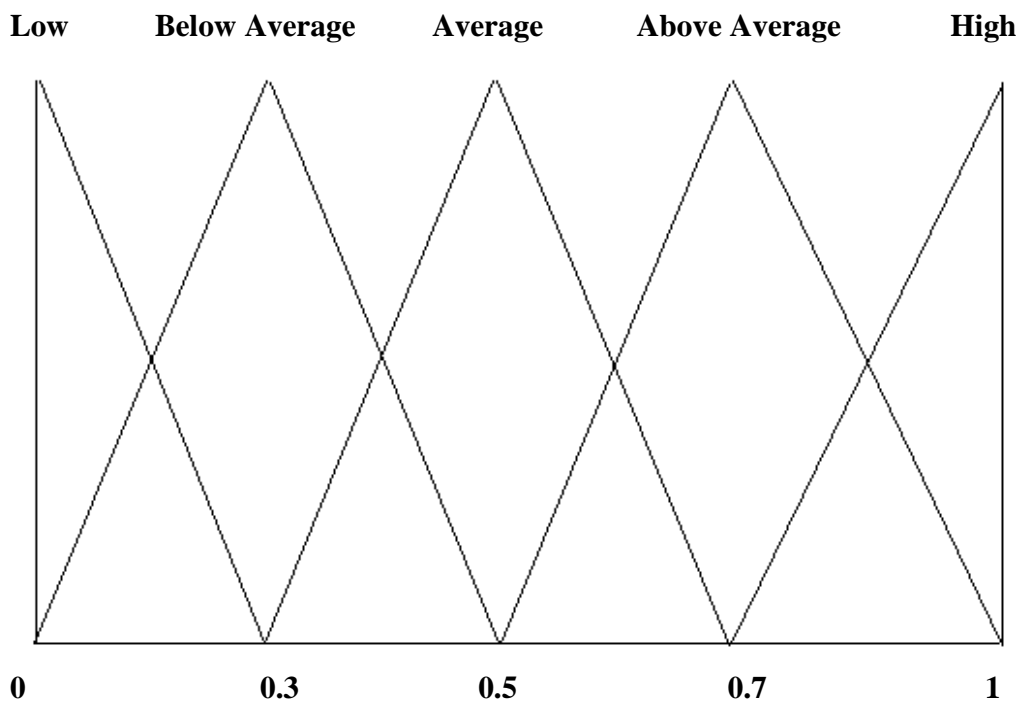

Figure 1: Fuzzification of linguistic terms to fuzzy numbers conversion 
Table 3: Linguistic Terms To Fuzzy Numbers Conversion

\begin{tabular}{|l|l|}
\hline $\begin{array}{l}\text { Linguistic } \\
\text { Terms }\end{array}$ & Fuzzy Number \\
\hline Low & M1 \\
\hline Below average & M2 \\
\hline Average & M3 \\
\hline Above average & M4 \\
\hline High & M5 \\
\hline
\end{tabular}

From above figure1,membership function of M1,M2,M3,M4 and M5 are written as:

$$
\begin{aligned}
& \mu_{\mathrm{M} 1}(\mathrm{x})=\left\{\begin{array}{l}
1, \mathrm{x}=0 \\
\frac{(0.3-x)}{0.3}, 0 \leq \mathrm{x} \leq 0.3
\end{array}\right. \\
& \mu_{\mathrm{M} 2}(\mathrm{x})= \begin{cases}\frac{(x-0)}{0.25}, & 0 \leq \mathrm{x} \leq 0.25 \\
\frac{(0.5-x)}{0.25}, & 0.25 \leq \mathrm{x} \leq 0.5\end{cases} \\
& \mu_{\mathrm{M} 3}(\mathrm{x})= \begin{cases}\frac{(x-0.3)}{0.2}, & 0.3 \leq \mathrm{x} \leq 0.5 \\
\frac{(0.7-x)}{0.2}, & 0.5 \leq \mathrm{x} \leq 0.7\end{cases} \\
& \mu_{\mathrm{M} 4}(\mathrm{x})= \begin{cases}\frac{(x-0.5)}{0.25}, & 0.5 \leq \mathrm{x} \leq 0.75 \\
\frac{(1.0-x)}{0.25}, & 0.75 \leq \mathrm{x} \leq 1\end{cases} \\
& \mu_{\mathrm{M} 5}(\mathrm{x})= \begin{cases}\frac{(x-0.7)}{0.3}, & 0.7 \leq \mathrm{x} \leq 1 \\
1, & \mathrm{x}=1\end{cases} \\
& \mu_{\mathrm{M} 5}(\mathrm{x})= \begin{cases}\frac{(x-0.7)}{0.3}, & 0.7 \leq \mathrm{x} \leq 1 \\
1, & \mathrm{x}=1\end{cases}
\end{aligned}
$$

The right, left and total scores are computed as follows for M1:-

$$
\begin{aligned}
& \mu_{\mathrm{R}}(\mathrm{M} 1)=\operatorname{Sup}\left[\mu_{\max }(\mathrm{x}) \wedge \mu_{\mathrm{M} 1}(\mathrm{x})\right]=0.23 \\
& \mu_{\mathrm{L}}(\mathrm{M} 1)=\operatorname{Sup}\left[\mu_{\min }(\mathrm{x})^{\wedge} \mu_{\mathrm{M} 1}(\mathrm{x})\right]=1
\end{aligned}
$$

And

$\mu_{\mathrm{T}}(\mathrm{M} 1)=\left[\mu_{\mathrm{R}}(\mathrm{M} 1)+1-\mu_{\mathrm{L}}(\mathrm{M} 1)\right] / 2=0.115$

Similarly, the right, left and total scores are computed for M2, M3, M4 and M5 and are tabulated in below table:

Table4: Membership Function Of M1, M2, M3, M4, M5

\begin{tabular}{|l|l|l|l|}
\hline $\mathbf{I}$ & $\boldsymbol{\mu}_{\mathbf{R}}(\mathbf{M i})$ & $\boldsymbol{\mu}_{\mathbf{L}}(\mathbf{M i})$ & $\boldsymbol{\mu}_{\mathbf{T}}(\mathbf{M i})$ \\
\hline 1 & 0.23 & 1.0 & 0.115 \\
\hline 2 & 0.39 & 0.8 & 0.295 \\
\hline 3 & 0.58 & 0.59 & 0.495 \\
\hline 4 & 0.79 & 0.4 & 0.695 \\
\hline 5 & 1.0 & 0.23 & 0.895 \\
\hline
\end{tabular}

Table5: Linguistic Terms With Their Corresponding Crisp Scores

\begin{tabular}{|l|l|l|}
\hline Linguistic Term & Fuzzy Number & Crisp Score \\
\hline Low & M1 & 0.115 \\
\hline Below Average & M2 & 0.295 \\
\hline Average & M3 & 0.495 \\
\hline Above Average & M4 & 0.695 \\
\hline High & M5 & 0.895 \\
\hline
\end{tabular}

Instead of assigning arbitrary values for various attributes, this fuzzy method reflects the exact linguistic descriptions in terms of crisp scores. Hence, it gives better approximations that are widely used.

\section{FAHP IN SOFTWARE ENGINEERING SCENARIO}

A Software developer wants to select an appropriate SDM for developing a software according to the requirement. In step 1 and 2 already we discuss about methodology and their selecting criteria.

In 2014, Jyoti verma, Sunita Bansal and Himanshu Pandey [3] publish a journal which develop a framework for selection of methodology. In this paper also develop a tool Modset which produce a rule combined with Likert scale. This paper also present comparison of methodology as above mention in section 2.2 in table 1 .Here we use only three selecting criteria such as Requirement specification and change incorporate( RS\&CI), Cost and Project size(PS) for ranking of three methodology Waterfall model, Spiral model and Prototype model.

In order to use Fuzzy AHP for SDM selection let us follow following step:

1) A decision making matrix based on above criteria with three fuzzy linguistic terms with three alternatives is shown below where SDM1 SDM2and SDM3 represent Waterfall model, Spiral model and Prototype model respectively.

Table6: Decision Making Matrix

\begin{tabular}{|l|l|l|l|}
\hline Methodology & RS\&CI & Cost & PS \\
\hline SDM1 & Low & Average & Average \\
\hline SDM2 & High & Average & Average \\
\hline SDM3 & Average & High & High \\
\hline
\end{tabular}

Instead of 5-point scale as explained above we have considered here 3-point scale for conversion of fuzzy linguistic term into crisp scores. Here we have used only 3point scale having the linguistic terms like low, average and high as shown in table.

From the above described Chen and Hwang (1992) method: 
Table7: The Conversion Of Linguistic Term In To Crisp Scores (3 Point Scale)

\begin{tabular}{|l|l|l|}
\hline Linguistic Term & Fuzzy Number & Crisp Score \\
\hline Low & M1 & 0.115 \\
\hline Average & M3 & 0.495 \\
\hline High & M5 & 0.895 \\
\hline
\end{tabular}

Fuzzy linguistic term of above table 6 is converted into crisp data using 3 point scale as shown in table 7 depicted in tables 8 below:

\section{Table 8: Conversion Of Fuzzy Linguistic Term Into Crisp} Data

\begin{tabular}{|l|l|l|l|}
\hline Methodology & RS\&CI & Cost & PS \\
\hline SDM1 & 0.115 & 0.495 & 0.495 \\
\hline SDM2 & 0.895 & 0.495 & 0.495 \\
\hline SDM3 & 0.495 & 0.895 & 0.895 \\
\hline
\end{tabular}

2) Now in this step we compare criteria with criteria by assigning comparative weights from Saaty's[7] nine point scale as shown in table 2 by applying heuristic knowledge in these domain.

So the Relative Importance Matrix can be written as:-

RS\&CI
Cost
PS $\left[\begin{array}{ccc}\mathrm{RS} \& C I & \text { Cost } & \text { PS } \\ 1 & 5 & 3 \\ 1 / 5 & 1 & 1 / 2 \\ 1 / 3 & 2 & 1\end{array}\right]$

Now calculating Geometric mean $(\mathrm{GM})$ for $\mathrm{i}^{\text {th }}$ row:-

$G M_{1}=(1 \times 5 \times 3)^{1 / 3}=2.4659, \quad G M_{2}=(1 / 5 \times 1 \times$ $1 / 2)^{1 / 3}=0.4641$ and $G M_{3}=(1 / 3 \times 2 \times 1)^{1 / 3}=0.873$,

Total Geometric mean GM=3.79

Hence the Normalized weights are: $W_{1}=2.46 / 3.79=0.649, W_{2}$ $=0.46 / 3.79=0.121$ and $W_{3}=0.87 / 3.79=0.229$

Now Consistency checking by using following equations below:

$A_{3}=A_{1} \times A_{2}$

So the $A_{3}=\left[\begin{array}{ccc}1 & 5 & 3 \\ 1 / 5 & 1 & 1 / 2 \\ 1 / 3 & 2 & 1\end{array}\right] \times\left[\begin{array}{c}0.649 \\ 0.121 \\ 0.229\end{array}\right]=\left[\begin{array}{c}1.914 \\ 0.36 \\ 0.678\end{array}\right]$

And $A_{4}=A_{3} / A_{2}$

$A_{4}=\left[\begin{array}{c}1.914 \\ 0.36 \\ 0.678\end{array}\right] \div\left[\begin{array}{l}0.649 \\ 0.121 \\ 0.229\end{array}\right]=\left[\begin{array}{c}2.949 \\ 2.975 \\ 3.0818\end{array}\right]$

And maximum value $\lambda_{\max }$ that is the average of matrix $A_{4}$ will be

$\lambda_{\text {max }}=\frac{(2.949+2.975+3.0818)}{3}=3.001$

Then consistency index $(\mathrm{CI})=\frac{\left(\lambda_{\max }-n\right)}{n-1}=\frac{(3.001-3)}{2}=0.0005$

And Consistency Ratio $(\mathrm{CR})=\frac{C I}{R I}=\frac{0.0005}{0.66}=0.001<0.1$
Hence the weights are consistent.

3) Now alternatives will be compared with alternatives for all the three criteria known as pair-wise comparison matrix. Three pair-wise comparison matrices are shown below:-

i. Pair wise comparison matrix for criteria RS\&CI:

\begin{tabular}{|c|c|c|c|}
\hline & SDM1 & SDM2 & SDM3 \\
\hline SDM & 1 & 0.895 & 0.115 \\
\hline $\mathrm{M} 2$ & $1 / 0.895$ & 1 & 0.115 \\
\hline SDM3 & $1 / 0.115$ & $1 / 0.115$ & 1. \\
\hline
\end{tabular}

Now calculating Geometric mean (GM) for $\mathrm{i}^{\text {th }}$ row:-

$G M_{1}=(1 \times 0.895 \times 0.115)^{1 / 3}=0.4686, G M_{2}=(1 / 0.895 \times$ $1 \times 0.115)^{1 / 3}=0.5046$ and $G M_{3}=(1 / 0.115 \times 1 / 0.115 \times$ $1)^{1 / 3}=4.2286$.

Total Geometric mean GM=5.201

Hence the Normalized weights are: $W_{1}=0.4686 / 5.201=$ $0.0900, W_{2}=0.5046 / 5.201=0.0970$ and $W_{3}=4.2286 / 5.201=$ 0.8130

Now Consistency checking by using following equations below:

$A_{3}=A_{1} \times A_{2}$

So the $A_{3}=\left[\begin{array}{ccc}1 & 0.895 & 0.115 \\ 1 / 0.895 & 1 & 0.115 \\ 1 / 0.115 & 1 / 0.115 & 1\end{array}\right] \times\left[\begin{array}{c}0.09 \\ 0.097 \\ 0.813\end{array}\right]=$ $\left[\begin{array}{l}0.27031 \\ 0.29105\end{array}\right.$

$\left[\begin{array}{c}0.29105 \\ 2.4390\end{array}\right]$

And $A_{4}=A_{3} / A_{2}$

$A_{4}=\left[\begin{array}{c}0.27031 \\ 0.29105 \\ 2.4390\end{array}\right] \div\left[\begin{array}{c}0.09 \\ 0.097 \\ 0.813\end{array}\right]=\left[\begin{array}{c}3.003 \\ 3.0005 \\ 3.000\end{array}\right]$

And maximum value $\lambda_{\max }$ that is the average of matrix $A_{4}$ will be

$\lambda_{\text {max }}=\frac{(3.003+3.0005+3.000)}{3}=3.0001$

Then consistency index $(\mathrm{CI})=\frac{\left(\lambda_{\max }-n\right)}{n-1}=\frac{(3.0001-3)}{2}=0.00058$

And Consistency Ratio $(\mathrm{CR})=\frac{C I}{R I}=\frac{0.00058}{0.66}=0.0008<0.1$

Hence the weights are consistent.

ii. Pair wise comparison matrix for criteria COST:

SDM1 1
SDM2 $\left[\begin{array}{ccc}\text { SDM1 } & \text { SDM2 } & \text { SDM3 } \\ 1 & 1 & 0.495 \\ 1 & 1 & 0.495 \\ 1 / 0.495 & 1 / 0.495 & 1\end{array}\right]$

Now calculating Geometric mean $(\mathrm{GM})$ for $\mathrm{i}^{\text {th }}$ row:-

$G M_{1}=(1 \times 1 \times 0.495)^{1 / 3}=0.7910, G M_{2}=(1 \times 1 \times$ $0.495)^{1 / 3}=0.7910$ and $G M_{3}=(1 / 0.495 \times 1 / 0.495 \times$ $1)^{1 / 3}=1.5980$.

Total Geometric mean GM=3.18 
Hence the Normalized weights are: $W_{1}=0.7910 / 3.18=$ $0.2487, W_{2}=0.7910 / 3.18=0.2487$ and $W_{3}=1.5980 / 3.18=$ 0.5025

Now Consistency checking by using following equations below:

$A_{3}=A_{1} \times A_{2}$

So the $A_{3}=\left[\begin{array}{ccc}1 & 1 & 0.495 \\ 1 & 1 & 0.495 \\ 1 / 0.495 & 1 / 0.495 & 1\end{array}\right] \times\left[\begin{array}{l}0.2487 \\ 0.2487 \\ 0.5025\end{array}\right]=$

$[0.7461]$

0.7461

1.5073

And $A_{4}=A_{3} / A_{2}$

$A_{4}=\left[\begin{array}{l}0.7461 \\ 0.7461 \\ 1.5073\end{array}\right] \div\left[\begin{array}{l}0.2487 \\ 0.2487 \\ 0.5025\end{array}\right]=\left[\begin{array}{c}3.0001 \\ 3.0001 \\ 3.000\end{array}\right]$

And maximum value $\lambda_{\max }$ that is the average of matrix $A_{4}$ will be

$\lambda_{\max }=\frac{(3.0001+3.0001+3.000)}{3}=3.0001$

Then consistency index $(\mathrm{CI})=\frac{\left(\lambda_{\max }-n\right)}{n-1}=\frac{(3.0001-3)}{2}=0.00058$

And Consistency Ratio $(\mathrm{CR})=\frac{C I}{R I}=\frac{0.00058}{0.66}=0.0008<0.1$

Hence the weights are consistent.

iii. Pair wise comparison matrix for criteria PS:

SDM1
SDM2 $\left[\begin{array}{ccc}\text { SDM1 } & \text { SDM2 } & \text { SDM3 } \\ 1 & 1 & 0.495 \\ 1 & 1 & 0.495 \\ 1 / 0.495 & 1 / 0.495 & 1\end{array}\right]$

Now calculating Geometric mean $(\mathrm{GM})$ for $\mathrm{i}^{\text {th }}$ row:-

$G M_{1}=(1 \times 1 \times 0.495)^{1 / 3}=0.7910, \quad G M_{2}=(1 \times 1 \times$ $0.495)^{1 / 3}=0.7910$ and $G M_{3}=(1 / 0.495 \times 1 / 0.495 \times$ $1)^{1 / 3}=1.5980$.

Total Geometric mean GM=3.18

Hence the Normalized weights are: $W_{1}=0.7910 / 3.18=$ $0.2487, W_{2}=0.7910 / 3.18=0.2487$ and $W_{3}=1.5980 / 3.18=$ 0.5025

Now Consistency checking by using following equations below:

$A_{3}=A_{1} \times A_{2}$

So the $A_{3}=\left[\begin{array}{ccc}1 & 1 & 0.495 \\ 1 & 1 & 0.495 \\ 1 / 0.495 & 1 / 0.495 & 1\end{array}\right] \times\left[\begin{array}{l}0.2487 \\ 0.2487 \\ 0.5025\end{array}\right]=$

$[0.7461]$

0.7461

1.5073

And $A_{4}=A_{3} / A_{2}$

$A_{4}=\left[\begin{array}{l}0.7461 \\ 0.7461 \\ 1.5073\end{array}\right] \div\left[\begin{array}{l}0.2487 \\ 0.2487 \\ 0.5025\end{array}\right]=\left[\begin{array}{c}3.0001 \\ 3.0001 \\ 3.000\end{array}\right]$
And maximum value $\lambda_{\max }$ that is the average of matrix $A_{4}$ will be

$\lambda_{\text {max }}=\frac{(3.0001+3.0001+3.000)}{3}=3.0001$

Then consistency index $(\mathrm{CI})=\frac{\left(\lambda_{\max }-n\right)}{n-1}=\frac{(3.0001-3)}{2}=0.00058$

And Consistency Ratio $(\mathrm{CR})=\frac{C I}{R I}=\frac{0.00058}{0.66}=0.0008<0.1$

Hence the weights are consistent.

4) A matrix is formed with the help of obtained weights in case of pair-wise comparison matrix for three different criteria as calculated in step 3 is

$$
\left[\begin{array}{ccc}
0.090 & 0.2487 & 0.2487 \\
0.097 & 0.2487 & 0.2487 \\
0.813 & 0.50250 & 0.5025
\end{array}\right]
$$

So the final rank can be obtain the overall or composite performance scores for the alternatives are:-

$$
\left[\begin{array}{ccc}
0.090 & 0.2487 & 0.2487 \\
0.097 & 0.2487 & 0.2487 \\
0.813 & 0.50250 & 0.5025
\end{array}\right] \times\left[\begin{array}{l}
0.649 \\
0.121 \\
0.229
\end{array}\right]=\left[\begin{array}{l}
0.1454 \\
0.1499 \\
0.7035
\end{array}\right]
$$

Deciding the rank according to the higher value of above matrix, hence ranking is SDM3, SDM2 and SDM1 i.e. Prototype model having higher precedence then Spiral model and Waterfall model.

\section{CONCLUSION}

This paper presents the selection of SDM using fuzzy AHP approach for selecting appropriate SDM according to their selecting criteria. Fuzzy AHP is multicriteria decision making methods which are used to solve problems whose qualities of the alternatives are conflicting. This paper shows selection of SDM among three SDM and three criteria and ranking decided by FAHP is SDM3, SDM2 and SDM1. In future we extent it with more SDM and more criteria for selection of SDM in real sense of software engineering scenario.

\section{REFERENCES}

[1] Hota H.S. , Sanjay kumar Singhai and Ragini Shukla, "Application of Fuzzy Analytic Hierarchy Method in Software Engineering Scenario" International Journal of Computer Applications (0975 - 8887) Volume 57No.21, November 2012

[2] Rohit Khurana , " Software Engineering Principles and Practices", Sedcond Edition, Vikash Publication

[3] Jyoti Verma, Sunita Bansal and Himanshu Pandey, "Develop Framework for Selecting Best Software Development Methodology" International Journal of Scientific \& Engineering Research, Volume 5, Issue 4, April-2014 ,ISSN 2229-5518.

[4] M.Ayman Al Ahmar, "Rule based expert system for selecting software development methodology", Journal of theoretical and Applied Science, 2005-2010.

[5] Abdur Rashid khan, Zia Ur Rehman and Hafeez Ullah Amin, “Knowledge based system's modeling for software process model selection", IJACSA, Vol.2, No.2, Feb2011

[6] Saaty, T. L., (1980), The Analytical Hierarchy Process, McGraw Hill, New York.

[7] R.Venkata Rao, "Decision making in the manufacturing environment", Springer-Verlag London Limited,2007 
[8] Zhu, K. J., Jing, Y., and Chang, D. Y., “A Discussion on Extent Analysis Method and Applications of FuzzyAHP”, European Journal of Operational Research, 116, 1999, pp. 450-456

[9] Santanu Kr.Mishra and Amitava Ray, "Software developer selection : a Holistic approach for an eclectic decision" International Journal of Computer Application, volume 47-No.1,June 2012.pp.12-18
[10] Saaty, T. L., (2001), Decision Making with Dependence and Feedback: Analytic Network Process, RWS Publications, Pittsburgh Saaty, T. L., (2001).

[11] Saaty, T. L., (1994), "Fundamentals of Decision Making and Priority Theory with the Analytical Hierarchy Process", RWS Publications, Pittsburgh. 